\title{
Systematic Review of Studies Measuring the Impact of Educational Programs against Homophobia, Transphobia and Queerophobia in Secondary Schools of North America, Western Europe and Australia
}

\author{
Germano Vera Cruz \\ Department of Sexology, Faculty of Human and Social Sciences, University of Quebec-Montreal, Montreal, \\ Canada \\ Email: germane.veracruz@gmail.com
}

Received 1 October 2015; accepted 16 November 2015; published 19 November 2015

Copyright (C) 2015 by author and Scientific Research Publishing Inc.

This work is licensed under the Creative Commons Attribution International License (CC BY).

http://creativecommons.org/licenses/by/4.0/

(c) (i) Open Access

\begin{abstract}
The objective of this study is to review the studies measuring the impact of extra-curricular and intra-curricular educational programs designed to reduce the prejudice, verbal, psychological and physical violence against LGBTQ students in secondary schools, and assess the degree of effectiveness of those programs to improve the situation of students from sexual minorities, as well as to change the attitude and behavior of heterosexual and cisgender students towards their LGBTQ peers. Given the inclusion and exclusion criteria, 13 studies were identified as relevant. The majority of these studies were on Gay-Straight Alliance (GSA), and the other focused on extracurricular seminars type programs (ECS) conducted by volunteers of LGBTQ associations and intracurricular programs (ICP) administered by teachers. On one hand, the results show a significant, systematic and sustainable positive impact of GSA on both the school life of LGBTQ students and on the attitudes and behaviors of heterosexual and cisgender students toward their colleagues from sexual minorities; on the other hand, the results show a less effectiveness of ECS/ICP to reduce prejudice, verbal abuse, psychological and physical violence against LGBT students.
\end{abstract}

\section{Keywords}

Anti-Homophobia, Anti-Transphobia, Secondary Schools, Program, Impact 


\section{Introduction}

The heterosexism, genderism, homophobia and transphobia are mechanisms of discrimination and social normalization that profoundly affect the lives of sexual minorities such as lesbians, gay, bisexual, transgender and queer (LGBTQ).

In Western societies, much of the abuse against LGBTQ youth is perpetrated in secondary schools (Berril, 1990; de Ven, 1995; Wernick, Woodford, \& Siden, 2010). Thus, for many LGBTQ youth, the school is often a place of marginalization and suffering because of verbal, psychological and physical violence they experience (Wernick, Dessel, Kulick, \& Graham, 2013; Wernick et al., 2010; Nadal, \& Griffin, 2011).

The heterosexist, genderist, homophobic and transphobic attitudes and behaviors in schools have a negative impact on LGBTQ students as individuals, but also on the school community as a whole (Poteat, Mereish, DiGiovanni, \& Koenig, 2011; Swearer, Turner, Givens, \& Pollack, 2008). Meta-analistic studies have shown that being a victim of bullying, discrimination and anti-gay or anti-transgender violence is linked to a higher incidence of mental health problems (depression, anxiety, suicidal ideation) and self-harm (suicide, substance abuse, risky sexual behavior) (Almeida, Johnson, Corliss, Molnar, \& Azreal, 2009; Poteat \& Espegale, 2007). In addition, in secondary schools, the normative institutional culture and expectations placed on young LGBTQ hinder the development of a positive self-identity, self-esteem and creates a hostile learning environment for LGBTQ students (Graham, 2012; Wernick et al., 2013). Some heterosexual students also suffer harassment, heterosexist, and genderist identity-based LGBTQ perceived on them (strict application of standards on gender) or by being witnesses of heterosexist and genderist violence (Silverschanz, Cortina, Konik, \& Magley, 2008; Kimmel, 2003; Rich, 1980).

Based upon the evidence that creation of a safer and more inclusive school environment is essential for the well-being and learning of all students, in Western countries (Australia and New Zealand included), from 80s, the associations for the defense of LGBTQ people began to ask schools to implement intra-curricular and/or extracurricular programs to fight heterosexism, genderism, homophobia and transphobia (Currie, Mayberry, \& Chenneville, 2012; McGuire, Anderson, Toomey, \& Russell, 2010).

Given the diversity of cultures and situations in different Western countries, intervention strategies in schools to fight heterosexism, genderism, homophobia and transphobia were varied and diverse. One of the strategies preferred in North America (US and English-speaking Canada) was the creation of LGBTQ-Straight Alliance extracurricular groups known as Gay-Straight Alliances that create a space of understanding and empathy between LGBTQ students and heterosexual/cisgender students (Fetner \& Kush, 2007; Heinze \& Horn, 2009; Poteat, Mereish, DiGiovanni, \& Scheer, 2013). Another strategy used to reduce prejudice against sexual minorities in schools and fight anti-LGBTQ violence, prioritized in Western European countries and in French-speak-ing Canada, Australia and New Zealand, was the creation of curricular programs administered by teachers or extracurricular seminar-style intervention programs administered by volunteers of LGBTQ associations (Heinze \& Horn, 2009; Poteat, 2013).

\subsection{Gay-Straight Alliances (GSA)}

GSA are extracurricular groups led by students and active in the campus of some secondary schools with the purpose of create a safe and supportive space to encourage the identity development and self-esteem of LGBTQ students; outreach and educate heterosexual, cisgender students and teaching staff on issues related to sexual minorities; fight against anti-LGBTQ violence in general (Fetner \& Kush, 2007; Griffin, Lee, Waugh, \& Beyer, 2004). The first GSA was formed in 1988 in Massachusetts, but the GSA really has widespread in the United States from the 2000s (Fetner \& Kush, 2007). For example, according estimations, there were over 4,000 GSA in US public schools in 2008 (Wernick et al., 2013).

\subsection{Extracurricular Seminar (ECS) and Intra-Curriculum Program (ICP)}

The ECS are kind of seminars designed by LGBTQ associations that take place in the classrooms of secondary schools, run by LGBTQ volunteers. In general, these seminars (e.g., Frohard-Dourlent, 2014) last between 90 minutes and two hours. After introducing themselves to students, volunteers recall the objectives of the seminar, stressing that they are also there to open a dialogue without judgment and that students are free to express their opinions. Secondly, in some seminars, volunteers play a short video showing young gays, lesbians, bisexual, transgender or queer whose stories cover a wide range of issues such as coming out, their experience of homo- 
phobia, transphobia and victimization suffered at school, but also family issues, ethnic, religious within LGBTQ people; in some seminars, instead of projecting videos, volunteers tell students their personal experiences as gays, lesbians bisexual, transgender or queer; in others, it does both. The personal stories projected through videos or narrated in vivo help start the "free" discussion that is supposed to be the most important element of the seminars. Note that these seminars were designed as a response to two problems which are commonly identified as a source of negative experiences and perceptions that LGBTQ youth have in schools: the invisibility of sexual minorities and social problems they face in schools and in societies at large (Almeida, Johnson, Corliss, Molnar, \& Azrael, 2009; Kosciw, Greytalk, Diaz, \& Bartkiewick, 2010). And the logic behind the seminars is the belief that by making visible LGBTQ people and bringing students to share their personal and their social stories (discrimination, victimization, etc.) this would reduce prejudices and negative attitudes against them.

ICP are programs against heterosexism, genderism, homophobia and transphobia implemented in high schools, typically designed by teachers and school boards and included in the regular education program with the goal of educating students on issues related to sexual minorities and reduce prejudice and verbal, psychological and physical anti-LGBTQ violence, and create a good learning environment for all students. These programs are based on pioneering studies by Greenberg (1975) whose results suggested that a series of lectures and group discussions on homosexuality and the projection of videos recorded on the lives of gay people created more open attitudes toward homosexuals by other students (written response after each session). These results were reinforced by other similar studies conducted by other researchers (Bleich, 1989; Croteau \& Kušek, 1992; Sears, 1992; Stevenson, 1988).

\section{Method}

\subsection{Purpose}

The purpose of this study is to make a review of research on the impact of extra-curricular and intra-curricular programs designed to reduce verbal, psychological and physical anti-LGBTQ violence (aggression and victimization by peers, bullying and homophobic, transphobic or queerophobic slurs, prejudice and marginalization) in secondary schools, and evaluate the effectiveness of these programs to improve the situation of LGBTQ students and in change the heterosexual and cisgender students attitude and behavior toward sexual minorities.

\subsection{Procedure}

We conducted a systematic search on Medline, PubMed, PsychINFO, ERIC, JSTOR and ERUDIT databases in October 2014, looking for articles from journals with a "peer review" mechanism. The keywords used in the search are: Anti-homophobia or anti-homosexuality or homonegativity, heterosexism or heteronormativity, and school or education impact.

\subsection{Search Strategy}

The database released 347 articles. Of these articles, 34 were removed because they were duplicates and 238 were removed because they were not directly related to the impact of educational programs against heterosexism, genderism, homophobia and transphobia in the school environment. Abstracts of the 75 remaining items were analyzed according to the following criteria: 1) a longitudinal pretest-posttest type studies of a minimum of three months, or a retrospective type studies; 2) a sample which is at least locally or regionally representative of the studied population; 3) studies that measure the impact of these programs not only on LGBTQ students, but also and primarily on non-LGBTQ students. Articles which the content summaries were not in accordance with these criteria were excluded.

Thus, taking into account the inclusion and exclusion criteria, 13 studies were identified as relevant. Eight studies are from the United States, two from Canada, one from France, Germany and Australia. The majority of studies (eight) are on GSA, and the others were either extracurricular seminars given by LGBTQ association volunteers (two) or on intra-curricular teaching programs (three). Four studies are longitudinal pretest-posttest designed and the remaining (nine) are retrospective researches. Most studies were published between 2010 and 2014, but the oldest article was published in 1984. The data from these articles were retrieved. We collected data for each item in a sheet, which included a description of the interventions or the programs evaluated, research instruments, samples and results. 


\section{Result}

\subsection{The Impact of the GSA}

First, regarding LGBTQ students themselves, all studies we consulted show that GSA have a very significant impact on the lives of LGBTQ students (Perrotti \& Westheimer, 2001). Indeed, LGBTQ participants in these studies have said that GSA contributed to the overall improvement in their academic performance, relationships with other students, as well as improved their own sense of identity, their feeling of physical and emotional safety within the school (Miceli, 2005; Perrotti \& Westheimer, 2001; Walls, Kane, \& Wisneski, 2010).

Thus, in a qualitative study conducted by Miceli (2005), student leaders and teachers have argued that GSA has created positive change by improving the way teachers handle issues of homophobia and anti-gay harassment, allowing LGBTQ students feel well integrated into the campus secondary schools. Griffin et al. (2004) also found that the visibility generated by GSA activism has promoted constructive boarding of the issues related to sexual minorities, contributing to a more inclusive school environment.

Other studies show that the presence of the GSA in secondary schools can also be linked to an increased sense of security against harassment from peers (Chesir-Teran \& Hughes, 2009; Toomey, Ryan, Diaz, \& Russell, 2011; Toomey, McGuire, \& Russell, 2012). In addition, the researchers found that LGBTQ youth who attended a school in which a GSA is present report significantly more favorable testimonies about their school experiences and they also report a lower level of alcohol and drugs use and less psychological distress, etc. (Heck, Flentje, \& Cochran, 2011; Perrotti \& Westheimer, 2001).

For example, a representative study (Walls et al., 2010) conducted in Colorado (USA) examined how the GSA affect the sexual minority youth by comparing the school experiences of three distinct groups of LGBTQ students: 1) those who attended schools without GSA, 2) those who attended schools with GSA but were not members, and 3) LGBTQ people who attended schools with GSA which they were members. The results indicate that the presence of the GSA has a positive effect on educational experiences in the three situations mentioned above.

Secondly, all the studies we consulted show a significant positive impact of the presence in schools of GSA on changing attitudes and behaviors of heterosexual/cisgender students toward LGBTQ students, positive impact characterized by lower insults, intimidation and transphobic, homophobic or queerophobic physical violence.

For example, an American retrospective research using a large sample, representative of the population of a state (Massachusetts) secondary students, shows that victimization and suicide or attempted suicide among LGBTQ students were significantly lower in schools with GSA compared to schools without (Goodenow, Szalacha, \& Westheimer, 2006).

Another example is the retrospective study by Worthen (2014) in the southeastern United States. Retrospectively applying an attitude scale towards LGBTQ to a representative sample of students from universities in several states $(n=805 ; 61 \%$ women and $39 \%$ men; mean age $=22)$, Worthen has examined how the presence or absence of GSA in secondary schools attended by participants when they were still in high school affected their attitudes towards LGBTQ people. Overall, the results of this study show that the presence of a GSA in high school is a positive indicator of strong positive attitude toward LGBTQ people, even taking into account many control variables. These results suggest that the presence of GSA in secondary schools can have important positive and quite durable effects on attitudes and behaviors of students towards people from sexual minorities.

The study by Saewyc, Konishi, Chiaki, Rose and Homma (2014) in Canada also reached similar conclusions. This study explored the relationship between the presence or absence and the time elapsed since the presence of GSA in secondary schools in British Columbia, and the level of anti-gay discrimination and the prevalence of suicidal ideation or suicide attempts among lesbians, gays, bisexuals, heterosexuals, mainly or exclusively heterosexual students. The results of this study $(n=21.708)$ show that LGB students were less likely to suffer discrimination, had less suicidal thoughts or less attempted suicide in the schools with a presence of GSA, and the more the time of program implementation increased (e.g., after three years of presence) the prevalence of discrimination ideas or suicide attempts decreased further.

\subsection{The Impact of the ECS and the ICP}

Regarding the impact of extracurricular seminars (ECS) and intra-curricular programs (ICP), the results of the studies we have consulted are conflicting or mixed. 
Although most studies (four) (Cerny \& Polyson, 1984; Clift, 1988; de Ven, 1995; Wells, 1989) reveal that the educational intervention like ECS and ICP initially made students become less hostile to LGBTQ peers; somehow, this positive effect wanes with time (regression). These studies suggest that among all students, usually it is the male students who are most resistant to change and regress more. For example, de Ven (1995) conducted a longitudinal pretest-posttest designed study, in Australia, to assess the impact on students of a school teaching module for reducing homophobia. The results indicate that the hostility towards homosexuals was significantly reduced for girls and boys first; however, the boys returned to the previous level of homophobia after a year of follow-up. Research carried out in France, for example, shows similar results (Frohard-Dourlent, 2014).

A study (one), among those we consulted, shows an overall lack of change in attitudes and behaviors of heterosexual students toward LGBTQ students. Indeed, the longitudinal pretest-posttest study (1 - 3 years, 36 schools, 3.616 students participating) conducted in the US states of Illinois and Kansas by Espelage, Low, Polanin and Brown (2013), whose objective was to assess the impact of intra-curricular programs administered in secondary schools to reduce violence (aggression, victimization by peers, homophobic slurs, and the sexual violence) shows that physical assaults of all kinds had decreased by $42 \%$, but the programs have not had a significant positive effect on the prevalence of homophobic verbal abuse or intimidation.

Some other studies (two) show a positive and lasting change in attitudes and behaviors of all students, in general, toward LGBTQ students, specifically. For example, Wernick et al. (2013) conducted a research in secondary schools in Michigan (USA) to determine the effectiveness of an anti-homophobic extracurricular program developed and administered by the LGBTQ youth (pretest-posttest research, with 832 participants). The results indicate that the program has had a lasting positive impact for all students (measured by the desire to intervene in case of seeing homophobic acts), however, also there has been more lasting positive effects in female students than in male students.

Another example is the study conducted in Canada by Saewyc et al. (2014). This study explored the relationship between existence or non-existence and the time elapsed since the implementation of explicit anti-homophobic policies in secondary schools in British Columbia. This study ( $n=21.708)$ shows that LGB students from schools with above-mentioned program were less likely to suffer insults and homophobic discrimination, had less ideas or made less suicide attempts compared to high school students who did not had this type of program. And the more the duration of the program implementation were, less the prevalence of the problems cited above.

\section{Discussion}

All recent research on GSA show that they have a significant and lasting positive impact on the school life of LGBTQ students, as they help reduce heterosexist, genderist, homophobic and transphobic attitudes and behaviors. GSA also create a supportive and inclusive environment for all students on campus of the secondary schools in which they are located (Miceli, 2005; Walls et al., 2010; Perrotti \& Westheimer, 2001; Saewyc et al., 2014; Worthen, 2014).

Some researchers attribute the positive impact of GSA more to global changes that they train on the campus in terms of knowledge and legitimacy of the issues related to sexual minorities (Miceli, 2005; Fetner \& Kush, 2007); whereas other researchers suggest that the positive influence that the GSA have on LGBTQ students and heterosexual/cisgender students is mainly due to social support that they provide to students from sexual minorities, by systematically denouncing homophobic, transphobic and queerophobic acts (Walls et al., 2010; Perrotti \& Westheimer, 2001; Saewyc et al., 2014; Worthen, 2014).

The matter of fact is that the mere presence of a GSA in high school has an impact on the overall climate of the campus, and this is quite in accord with the objective inherent in their designs: "seek to reverse the influence of educational institutions that help instill prejudices and discrimination, harassment and abuse of homosexuals in schools, force these institutions to adopt the ideas of tolerance and respect for social diversity” (Miceli, 2005: p. 9). The very name "Gay-Straight Alliance”, a kind of pact between LGBTQ students and heterosexual/cisgender students that are already aware of these problems itself implies a change of perspective in the sense that the task to deal with sexual minorities is not incubated only to the LGBTQ members, but also to all students of good will (Miceli, 2005).

Indeed, the GSA was created based on the studies that have examined the role that, in a system of discrimination and oppression, privileged people can play a big role by working as allies of the oppressed and helping them to combat injustice they face, deconstructing the mechanisms underlying the discriminatory or oppressive 
system itself (e.g., Broido \& Reason, 2005; Edwards, 2006; Goodman, 2000; Jordan, 2012). Thus, it seems that the effectiveness of GSA come from the impact that theses extracurricular groups succeed to print not only on the attitudes and behaviors of isolated individuals but especially on the entire socio-institutional system.

In contrast, the extracurricular seminars and intra-curricular educational programs designed to reduce heterosexist, genderist, homophobic and transphobic attitudes and behaviors in secondary schools seem to have a limited positive impact (Cerny \& Polyson, 1984; Clift, 1988; de Ven, 1995; Frohard-Dourlent, 2014; Espelage et al., 2013; Wells, 1989).

Certainly, the small number of longitudinal studies on the impact of ECS/ICP, compared to those made on the impact of GSA does not allow a definitive conclusion on their relative lower efficiency. Nevertheless, it seems that the intrinsic characteristics of the ECS and the ICP themselves are not likely to cause profound changes.

Indeed, for instance, extracurricular seminars run by volunteers of LGBTQ associations are set up as a kind of dialogue between LGBTQ volunteers and the students that are generally supposed to hold many prejudices about homosexuality or transsexuality (Frohard-Dourlent, 2014). They are supposed to give students the opportunity to meet young gays, lesbians and transsexuals who identify themselves as such; and students are encouraged to take advantage of this opportunity to make all their questions about homosexuality and transsexuality. Thereby, contact with LGBTQ in flesh and bone and listen to their personal stories, being able to freely express all the questions and the doubts ones have about homosexuality and transphobia is supposed to reduce prejudices and thus lead to a change in attitudes and behaviors of students toward their LGBTQ peers (Frohard-Dourlent, 2014).

But, as so aptly noted Ellsworth (1992), critical of this type of dialogue, act as if the classroom was a safe space in which democratic dialogue was possible and that students could express themselves freely does not necessarily make it be so; and it would be foolish to believe that these seminars allow a genuine dialogue (Orner, 1992), capable of creating awareness, being more likely that LGBTQ volunteers are considered by some school students, consciously or not, as "judges and parts”, against which ones must resist. In addition, a classroom can never be separated from the context in which it is inserted, and in a society where prejudices are still stuck in institutions (family, school, institutionalized networks of cultural socialization, educational or recreational), it is difficult to change the attitudes and behaviors of individuals without first changing the attitudes and behaviors of institutions themselves.

Another likely problem that may affect the effectiveness of seminars dialogic type is that they can be rendered ineffective due to the presence of a complex intersectionality of privileges and disadvantages, favoritism and discrimination, real or symbolic, between the different categories of students and LGBTQ volunteers themselves; all this can make the dialogue between the actors unbalanced, difficult or ineffective.

Regarding the ICP, they are often based on the assumption that individuals are rational in their judgment and a series of lectures on the lives of sexual minorities and on the negative consequences that homophobia/transphobia has on LGBTQ people may cause awareness and thus change attitudes and behaviors in a sustainable manner (Goldberg, 1993). They assume that give to know the "facts" will reduce levels of prejudice. The notion that students are homophobic because they are ignorant not only implies the false idea that homophobia is an individual act rather than systemic (Luhmann, 1998), but that also ignore the complex ways in which people interact with "knowledge", including the fact that individuals can withstand rational arguments (Britzman, 1998; Dion, 2004; Memmi, 2002; Yep, 1997).

\section{Conclusion and Recommendations}

It seems that, in the light of the results of this review, which showed a large impact of GSA and less impact of ECS/ICP programs, for more efficiency in the fight against heterosexism, genderism, homophobia and transphobia in secondary schools, it would be better to encourage, along with ECS/ICP programs, the installation of associations groups like GSA.

It is true that the GSA has installed more easily in the United States and English-speaking Canada, since the socio-educational system of those country has a long tradition of existence of extracurricular "clubs” (purely recreational or cultural, intellectual or socio-politic, with specific objectives or not).

But we can consider, in other western countries, for example, the possibility of creating an alliance between subgroups of LGBTQ students and heterosexual/cisgender students within student associations, responsible for developing actions similar to those developed by GSA in countries where they are traditionally located. 


\section{References}

Almeida, J., Johnson, R. M., Corliss, H. L., Molnar, B. E., \& Azrael, D. (2009). Emotional Distress among LGBT Youth: The Influence of Perceived Discrimination Based on Sexual Orientation. Journal of Youth and Adolescence, 38, 10011014. http://dx.doi.org/10.1007/s10964-009-9397-9

Berrill, K. T. (1990). Anti-Gay Violence and Victimization in the United States: An Overview. Journal of Interpersonal Violence, 5, 274-294. http://dx.doi.org/10.1177/088626090005003003

Bleich, D. (1989). Homophobia and Sexism as Popular Values. Feminist Teacher, 4, 21-28.

Britzman, D. (1998). Lost Subjects, Contested Objects: Toward a Psychology of Learning. Albany, NY: State University of New York Press.

Broido, E. M., \& Reason, R. D. (2005). The Development of Social Justice Attitudes and Actions: An Overview of Current understandings. New Directions for Student Services, 110, 17-28. http://dx.doi.org/10.1002/ss.162

Cerny, J. A., \& Polyson, J. (1984). Changing Homonegative Attitudes. Journal of Social and Clinical Psychology, 2, 366-371. http://dx.doi.org/10.1521/jscp.1984.2.4.366

Croteau, J. M., \& Kusek, M. T. (1992). Gay and Lesbian Speaker Panels: Implementation and Research. Journal of Counseling and Development, 70, 396-401. http://dx.doi.org/10.1002/j.1556-6676.1992.tb01623.x

Chesir-Teran, D., \& Hughes, D. (2009). Heterosexism in High School and Victimization among Lesbian, Gay, Bisexual, and Questioning Students. Journal of Youth and Adolescence, 38, 963-975. http://dx.doi.org/10.1007/s10964-008-9364-X

Clift, S. M. (1988). Lesbian and Gay Issues in Education: A Study of the Attitudes of First Year Students in a College of Higher Education. British Educational Research Journal, 14, 31-50. http://dx.doi.org/10.1080/0141192880140103

Currie, S., Mayberry, M., \& Chenneville, T. (2012). Destabilizing Anti-Gay Environments through Gay-Straight Alliances: Possibilities and Limitations through Shifting Discourses. The Clearing House: A Journal of Educational Strategies, Issues and Ideas, 85, 56-60. http://dx.doi.org/10.1080/00098655.2011.611190

De Ven, P. V. (1995). Effects on High School Students of a Teaching Module for Reducing Homophobia. Basic and Applied Social Psychology, 17, 153-172. http://dx.doi.org/10.1080/01973533.1995.9646137

Dion, S. (2004). (Re)telling to Disrupt: Aboriginal People and the Stories of Canadian History. Journal of the Canadian Association for Curriculum Studies, 2, 55-76.

Edwards, K. (2006). Aspiring Social Justice Ally Identity Development: A Conceptual Model. NASPA Journal, 43, 39-60.

Ellsworth, E. (1992). Why Doesn't Feel Empowering? Working through the Repressive Myths of Critical Pedagoy. In C. Luke, \& J. Gore (Eds.), Feminism and Critical Pedagogy (pp. 90-119). New York: Routledge.

Espelage, D. L., Low, S., Polanin, J. R., \& Brown, E. C. (2013). The Impact of a Middle School Program to Reduce Aggression, Victimization, and Sexual Violence. Journal of Adolescent Health, 53, 180-186.

http://dx.doi.org/10.1016/j.jadohealth.2013.02.021

Fetner, T., \& Kush, K. (2007). Gay-Straight Alliances in High Schools: Social Predictors of Early Adoption. Youth \& Society, 40, 114-130. http://dx.doi.org/10.1177/0044118X07308073

Frohard-Dourlent, H. (2014). Working to "Increase Respect and Reduce Stigma": Thinking through the Possibilities and Limits of an Antihomophobia Education Program in Paris. Journal of LGBT Youth, 9, 1-21. http://dx.doi.org/10.1080/19361653.2011.627835

Goldberg, D. (1993). Racist Culture: Philosophy and the Politics of Meaning. Cambridge, MA: Blackwell.

Goodenow, C., Szalacha, L., \& Westheimer, K. (2006). School Support Groups, Other School Factors, and the Safety of Sexual Minority Adolescents. Psychology in the Schools, 43, 573-589. http://dx.doi.org/10.1002/pits.20173

Goodman, D. J. (2000). Motivating People from Privilege Groups to Support Social Justice. Teachers College Record, 102, 1061-1085. http://dx.doi.org/10.1111/0161-4681.00092

Graham, L. F. (2012). Psychosocial Health of Black Sexually Marginalized Men. In H. M. Treadwell, C. Xanthos, \& K. B. Holden (Eds.), Social Determinants of Health among African American Men (pp. 63-81). San Francisco, CA: Wiley \& Sons.

Greenberg, J. S. (1975). A Study of Personality Change Associated with Conducting a High School Unit on Homosexuality. Journal of School Health, 45, 394-398. http://dx.doi.org/10.1111/j.1746-1561.1975.tb04501.x

Griffin, D., Lee, C., Waugh, J., \& Beyer, C. (2004). Describing Roles That Gay-Straight Alliances Play in Schools: From Individual Support to Social Change. Journal of Gay and Lesbian Issues in Education, 1, 7-22. http://dx.doi.org/10.1300/J367v01n03 03

Heck, N., Flentje, A., \& Cochran, B. (2011). Offset Ting Risks: High School Gay-Straight Alliances and Lesbian, Gay, Bisexual, and Transgender (LGBT) Youth. School Psychology Quarterly, 26, 161-174. http://dx.doi.org/10.1037/a0023226 
Heinze, J. E., \& Horn, S. S. (2009). Intergroup Contact and Beliefs about Homosexuality in Adolescence. Journal of Youth and Adolescence, 38, 937-951. http://dx.doi.org/10.1007/s10964-009-9408-x

Jordan, M. L. (2012). Heterosexual Ally Identity Development: A Conceptual Model. Journal of the Indiana University Student Personnel Association, 2012, 67-78.

Kimmel, M. S., \& Mahler, M. (2003). Adolescent Masculinity, Homophobia, and Violence: Random School Shootings, 1982-2001. American Behavioral Scientist, 46, 1439-1458. http://dx.doi.org/10.1177/0002764203046010010

Kosciw, J. G., Greytak, E. A., Diaz, E. M., \& Bartkiewicz, M. J. (2010). The 2009 National School Climate Survey: The Experiences of Lesbian, Gay, Bisexual, and Transgender Youth in Our Nation's Schools. Washington DC: Gay Lesbian and Straight Education Network.

Luhmann, S. (1998). Queering/Querying Pedagogy? Or, Pedagogy Is Pretty Queer Thing. In W. Pinar (Ed.), Queer Theory in Education (pp. 141-155). Hillsdale, NJ: Lawrence Erlbaum.

McGuire, J. K., Anderson, C. R., Toomey, R. B., \& Russell, S. T. (2010). School Climate for Transgender Youth: A Mixed Method Investigation of Student Experiences and School Responses. Journal of Youth and Adolescence, 39, 1175-1188. http://dx.doi.org/10.1007/s10964-010-9540-7

Memmi, A. (2002). Racism. S. Martinot, (Trans.), Minneapolis, MN: University of Minnesota Press.

Miceli, M. (2005). Standing Out, Standing Together: The Social and Political Impact of Gay-Straight Alliances. New York: Routledge.

Nadal, K. L., \& Griffin, K. E. (2011). Microaggressions: A Root of Bullying, Violence, and Victimization toward Lesbian, Gay, Bisexual, and Transgender Youths. In M. A. Paludi (Ed.), The Psychology of Teen Violence and Victimization (Vol. 1, pp. 3-22).

Orner, M. (1992). Interrupting the Calls for Student Voice in "Liberatory” Education: A Feminist Post Structuralist Perspective. In C. Luke, \& J. Gore (Eds.), Feminism and Critical Pedagogy (pp. 74-89). New York: Routledge.

Perrotti, J., \& Westheimer, K. (2001). When the Drama Club Is Not Enough: Lessons from the Massachussetts Safe Schools Program for Gay and Lesbian Students. Boston, MA: Beacon Press.

Poteat, V. P., \& Espelage, D. L. (2007). Predicting Psychosocial Consequences of Homophobic Victimization in Middle School Students. The Journal of Early Adolescence, 27, 175-191. http://dx.doi.org/10.1177/0272431606294839

Poteat, V. P., Mereish, E. H., DiGiovanni, C. D., \& Koenig, B. W. (2011). The Effects of General and Homophobic Victimization on Adolescents' Psychosocial and Educational Concerns: The Importance of Intersecting Identities and Parent Support. Journal of Counseling Psychology, 58, 597-609. http://dx.doi.org/10.1037/a0025095

Poteat, V. P., Mereish, E. H., DiGiovanni, C. D., \& Scheer, J. R. (2013). Homophobic Bulling. In I. Riversand, \& N. Duncan (Eds.), Bullying: Experiences and Discourses of Sexuality and Gender (pp. 76-95). New York: Routledge.

Rich, A. (1980). Compulsory Heterosexuality and Lesbian Existence. Signs, 5, 631-660. http://dx.doi.org/10.1086/493756

Saewyc, E. M., Konishi, C., Rose, H. A., \& Homma, Y. (2014). School-Based Strategies to Reduce Suididal Ideation, Suicide Attempts, and Discrimination among Sexual Minority and Heterosexual Adolesents in Western Canada. International Journal of Child, Youth and Family Studies, 1, 89-112.

Sears, J. T. (1992). Researching the Other/Searching for Self: Qualitative Research on Homosexuality in Education. Theory into Practice, 30, 147-156. http://dx.doi.org/10.1080/00405849209543536

Silverschanz, P., Cortina, L. M., Konik, J., \& Magley, V. J. (2008). Slurs, Snubs, and Queer Jokes: Incidence and Impact of Heterosexist Harassment in Academia. Sex Roles, 58, 179-191. http://dx.doi.org/10.1007/s11199-007-9329-7

Stevenson, M. R. (1988). Promoting Tolerance of Homosexuality. An Evaluation of Intervention Strategies. The Journal of Sex Research, 35, 500-511. http://dx.doi.org/10.1080/00224498809551478

Swearer, S. M., Turner, R. K., Givens, J. E., \& Pollack, W. S. (2008). “You're So Gay!”: Do Different Forms of Bullying Matter for Adolescent Males? School Psychology Review, 37, 160-173.

Toomey, R. B., McGuire, J. K., \& Russell, S. T. (2012). Heteronormativity, School Climates, and Perceived Safety for Gender Non Conforming Peers. Journal of Adolescence, 35, 187-196. http://dx.doi.org/10.1016/j.adolescence.2011.03.001

Toomey, R., Ryan, C., Diaz, R., \& Russell, S. (2011). High School Gay-Straight Alliances (GSAs) and Young Adult WellBeing: An Examination of GSA Presence, Participation, and Perceived Effectiveness. Applied Developmental Science, 15, 175-185. http://dx.doi.org/10.1080/10888691.2011.607378

Walls, N. E., Kane, S. B., \& Wisneski, H. (2010). Gay-Straight Alliances and School Experiences of Sexual Minority Youth. Youth \& Society, 41, 307-332. http://dx.doi.org/10.1177/0044118X09334957

Wells, J. W. (1989). Teaching about Gay and Lesbian Sexual and Affectional Orientation Using Explicit Films to Reduce Homophobia. Journal of Humanistic Education and Development, 28, 18-34.

http://dx.doi.org/10.1002/j.2164-4683.1989.tb00179.x 
Wernick, L. J., Kulick, A., \& Inglehart, M. H. (2013). Factors Predicting Student Intervention When Witnessing AntiLGBTQ Harassment: The Influence of Peers, Teachers and Climate. Children and Youth Services Review, 35, $296-301$. http://dx.doi.org/10.1016/j.childyouth.2012.11.003

Wernick, L. J., Woodford, M., \& Siden, J. Y. (2010). Youth-Led Participatory Action Research: Fostering Effective YouthAdult Partnerships_A Case Study. In L. Harter, J. Hamel-Lambert, \& J. Millesen (Eds.), Participatory Partnerships for Social Action and Research (pp. 165-186). Dubuque, IA: Kendall/Hunt Publishing.

Wernick, L. J., Dessel, A. B., Kulick, A., \& Graham, L. F. (2013). LGBTQQ Youth Change: Developing Allies against Bulling through Performance and Dialogue. Children and Youth Services Review, 35, 1576-1586. http://dx.doi.org/10.1016/j.childyouth.2013.06.005

Worthen, M. G. F. (2014). The Interactive Impact of High School Gay-Straight Alliances on College Student Attitudes toward LGBT Individuals: An Investigation of High School Characteristics. Journal of Homosexuality, 61, 217-250. http://dx.doi.org/10.1080/00918369.2013.839906

Yep, G. A. (1997). Changing Homophobic and Heterosexist Attitudes. In J. T. Sears, \& W. L. Williams (Eds.), Overcoming Heterosexism and Homophobia: Strategies That Work (pp. 49-64). New York: Columbia University Press. 